\title{
Miconias do Estado do Rio de Janeiro Seção Chaenanthera Naudin (Melas- tomataceae)
}

José Fernando A. Baumgratz ${ }^{1}$

1 Biólogo do Jardim Botânico do Rio de Janeiro e bolsista do CNPq.

$O$ autor agradece às Dras. Graziela Maciel Barroso e Maria do Carmo M. Marques; ao CNPq; aos Drs. H. Merxmüller e H. Roessler, do Botanische Staatssamm/ung; ao Dr. J.J. Wurdack, do Smithsonian Institution; aos diretores e curadores das instituições nacionais e estrangeiras, pelo empréstimo de suas coleções conforme relação material examinado.

O autor apresenta neste trabalho o estudo taxonômico das espécies do gênero Miconia Ruiz et Pav., integrantes da seção Chaenanthera Naud., ocorrentes no Estado do Rio de Janeiro. $O$ tratamento dado à seção assinala três espécies e duas variedades, com descrições, ilustrações $e$ fotografias, salientando o tipo de deiscência e forma das anteras, ocorrência de domácias, margem das folhas, pilosidade da inflorescência, hipanto, ovário e fruto. Também são apresentadas novas sinonímias para as espécies típicas de $M$. pusilliflora e $M$. rigidiuscula, bem como uma chave analítica para o reconhecimento das espécies e variedades.

\section{Introdução}

Dando prosseguimento ao estudo taxonômico do gênero Miconia Ruiz et Pav. para o Estado do Rio de Janeiro (Baumgratz, 1980 e 1982), apresentamos neste trabalho as integrantes da seção Chaenanthera Naud.

Em vista da grande afinidade entre as espécies desta seção é freqüente encontrarmos o material dos herbários identificados de maneira imprecisa ou mesmo incorreta. Vem contribuir ainda para este fato a natureza duvidosa no que diz respeito à deiscência das anteras.

Realizando uma investigação minuciosa nas obras princeps das espécies e, conseqüentemente, da referida seção, observamos que ao longo da história, diferentes foram as interpretações feitas quanto à caracterização desta seção e seus taxa, que estão baseadas, principalmente, no processo de deiscência da antera. Por essa razão é comum haver, na literatura, uma controvérsia quanto ao tipo de deiscência, ora descrita como rimosa ora como poricida, para algumas das espécies.

A deiscência rimosa das anteras não é um caráter muito comum na família $\mathrm{Me}$ lastomataceae e seu estudo vem a ser de grande importância para o conhecimento da filogenia do gênero $e$, conseqüentemente, da fam ́lia. Deste modo, não enquadramos nesta seção as espécies $M$. latecrenata (DC.) Naud., M. sellowiana Naud., M. inaequidens (DC.) Naud., M. elaeodendron (DC.) Naud. e M. urophylla DC., inicialmente levantadas para a área em estudo, em virtude da deiscência poricida de suas anteras. Também não as incluímos em outra seção por necessitarem ainda de novas investigações de seus caracteres morfológicos essenciais à sua sistemática e de supormos que estas espécies possam vir a constituir uma nova seção para o gênero Miconia, uma vez que se trata, provavelmente, de um grupo de transição entre aqueles de deiscência rimosa e poricida.

\section{Material e métodos}

Neste estudo taxonômico utilizamos o material botânico obtido das coleções depositadas nos herbários do Jardim Botânico do Rio de Janeiro, Museu Nacional do Rio de Janeiro e do Herbário Bradeanum, bem como o de outras instituições estrangeiras, cedido por empréstimo, examinando, quando possível, os tipos dos taxa.

Para análise dos detalhes florais de cada espécie, clarificamos inicialmente 
suas peças florais em $\mathrm{NaOH}$ a $5 \%$, que em seguida foram submetidas a hipoclorito de sódio a $50 \%$ e posteriormente lavadas em água corrente e montadas em água-glicerina a $50 \%$ para observação em visão frontal.

$\mathrm{Na}$ diafanização das folhas empregamos a técnica de Strittmatter (1973), utilizando um pequeno recurso técnico. Como as folhas das espécies em pauta são muito membranáceas foi necessária a colocação de lâminas sobre as mesmas, antes de se iniciar todo o processo técnico, uma vez que elas já em $\mathrm{NaOH}$ começavam a enrolar-se, danificando-se totalmente. Mesmo realizando tal técnica à quente (em estufa a $50^{\circ} \mathrm{C}$ ) e, neste caso, utilizando $\mathrm{NaOH}+$ álcool $96^{\circ} \mathrm{C}$, verificamos o mesmo comportamento anterior. Por esta razão o material permaneceu sob lâmina por cerca de 24 horas, até ser submetido ao hipoclorito de sódio. Em seguida continuamos normalmente o processo, corando as folhas com safranina hidroalcoólica a $5 \%$ e montando-as em xarope de Apathy. As mesmas foram fotografadas e observadas em visão frontal para estabelecermos os padrões de nervação e detalhes da base, margem e ápice foliar.

No estudo da nervação e forma das folhas adotamos o conceito de Hickey (1974) e na classificação das domácias o de Stace (1965). Para a observação e ilustração das domácias utilizamos material diafanizado.

Para a realização dos desenhos que ilustram o presente trabalho usamos microscópio óptico e estereoscópico, com suas respectivas câmaras claras em diferentes escalas de aumento.

\section{Resultados}

\section{Seção Chaenanthera Naudin}

Naudin, Ann. Sci. Nat. sér. 3(16):238. 1851 , p.p.; Cogniaux in Martius, FI. Bras. $14(4): 388$. 1887, p.p.; idem in A. et C. De Candolle, Mon. Phan. 7:856. 1891, p.p.

Cremanium Don, Mem, Wern. Soc. 4:310. 1823, p.p.; DC., Prodr. 3:191. 1828, p.p. Chariantheae DC., loc. cit.:196; Benth. in Hook., Journ. Bot. 2:287. 1840.

Chaenopleura Rich. ex DC., loc. cit.:197; Benth. in Hook., loc. cit.:315; Gardn. in Hook., Lond. Journ. Bot. 2:349. 1843;
Benth. et Hook., Gen. PI. 1:764. 1862. Pleurochaenia Griseb., FI. Brit. W. Ind. Isl. 1(2):260. 1860; Benth. et Hook., loc. cit., pro syn.

Eurychaenia Griseb., loc. cit.:258; Benth. et Hook., loc. cit., pro syn.

Chaenopleura Crueg. in Griseb., loc. cit.: 259.

Hypoxanthus Rich. ex Benth. et Hook., loc. cit., p.p.; Triana, Trans. Linn. Soc. Bot. 28:100. 1871, p.p.

Naudin (1851) caracterizou esta seção pela deiscência rimosa das anteras, com uma ou duas rimas, enquanto Cogniaux (1887) acrescentou ainda as flores tetrâmeras ou petâmeras, pequenas, com cálice campanulado ou subesférico, de limbo persistente ou decíduo, truncado ou brevemente lobado, com a face externa dos lobos freqüentemente tuberculada, pétala geralmente obovada, de ápice arredondado ou retuso, anteras pequenas, lineares, quase retas, com o conectivo comumente pouco prolongado abaixo dos lóculos, base inapendiculada ou raramente com um curto apêndice.

Entretanto, de acordo com nossas observações podemos assinalar como característica principal desta seção a deiscência rimosa das anteras, feita por apenas uma rima, desde o ápice até à base, sobre a região do septo na face ventral e sua forma oblonga quando deiscentes. Ainda como características desta seção encontramos as flores tetrâmeras ou pentâmeras, cálice 4-5-lobado, com os lobos caducos e apresentando a porção mediana carnosa e aguda dorsalmente, conectivo levemente prolongado abaixo dos lóculos, inapendiculado ou breve calcarado em $M$. crassinervia Cogn. e $M$. solmsii Cogn. (Cogniaux, 1887), fruto com 1-3 sementes por lóculo, obovadas, convexas no dorso, testa lisa (com exceção de $M$. hypoleuca Triana, que possui de 13-20 sementes por lóculo, triangulares).

Como características comuns às espécies estudadas podemos também assinalar: ramos - cilíndricos, achatados em direção ao ápice e glabrescentes; folhas - simples, decussadas, pecioladas, sem estípulas; pecíolos estriados e glabrescentes; padrão de nervação com três nervuras curvinérvias, proeminentes na face dorsal, subparalelas, de desenvolvimento perfeito, sendo a mediana mais espessa em relação às laterais, ocorrendo ainda duas nervuras paralelas aos bordos, inconspícuas; inflo- rescência - sinflorescências terminais com tirsos parciais, apresentando no eixo principal e nos parciais uma, raro duas flores terminais (figura 7 ); ramos decussados com bractéolas na base, caducas; flores - alvas, hermafroditas, actinomorfas, diplostêmones, com bractéolas caducas na base; lobos do cálice caducos e membranáceos, com a porção mediana carnosa e aguda dorsalmente; hipanto campanulado; pétalas livres, de oblongas a obovadas, apresentando no ápice papilas de cutícula estriada em ambas as faces; estames livres, exsertos; anteras bitecas, com o conectivo levemente prolongado abaixo dos lóculos, inapendiculado; filetes achatados, geniculados e glabros; ovário ínfero, trilocular (às vezes dois lóculos em $M$. rigidiuscula), com um óvulo por lóculo; estilete dilatado no ápice, glabro; estigma truncado; fruto - baga, globoso ou subgloboso; sementes obovadas, convexas no dorso, com testa lisa e fulvo-pardacenta.

\section{Chave para Identificação dos Taxa}

1 - Presença de domácias do tipo marsupiforme, axilar-primárias, na face dorsal da lâmina foliar (figura 3(1 e 1a) e figura $8(2))$; ovário glabro, às vezes, pulverulento;

2. Folhas com margem inteira, às vezes, levemente ondulada (figura 3(2) e figura $4(2)) \ldots \ldots \ldots \ldots . . . .$. . . . M. pusilliflora var. pusilliflora

2': Folhas com margem serreada, dentada ou crenulada, principalmente da região mediana para o ápice;

3- Folhas com margem dentada ou crenulada (figura $4(1)$ ); ramos da inflorescência e hipanto revestidos densamente de diminutos pêlos estrelados; fruto com diminutos pêlos estrelados, bem evidentes no ápice e na base . . . . . . .M. pusilliflora var. intermedia

3'- Folhas com margem 2/3-serreada para o ápice (figura 8(1 e 3)); ramos e hipanto glabrescentes; fruto glabro (figura $9(7)$ ) . . . . . . .......... M. hymenonervia

1'- Ausência de domácias na face dorsal da lâmina foliar (figura 11(1)); ovário com pêlos estrelados no ápice;

4- Ramos, pecíolos e face dorsal da lâmina foliar glabrescentes. . . . . . . . . M. rigidiuscula var. rigidiuscula 4 - Ramos, principalmente os das extremidades da planta, pecíolos e as nervuras principais na face dorsal da 
lâmina foliar densamente revestidos de diminutos pêlos estrelados ferrugíneos .............. . .M. rigidiuscula var. purpurascens Miconia pusilliflora (DC.) Naud.

Naudin, Ann. Sci. Nat. sér. 3(16):171. 1851; Wurdack, Sellowia 14:163. 1962.

Árvore pequena, de 3-6m de altura. Pecíolos com $0,5-1,8 \mathrm{~cm}$ de comprimento; lâmina foliar de $5-18,5 \mathrm{~cm}$ de comprimento e $1,6-6,3 \mathrm{~cm}$ de largura, de elíptica a lanceolada, base agudo-cuneada ou decorrente, raro obtusa, com ápice atenuado-caudado, às vezes falcado, membranácea, com a face ventral glabra e a face dorsal glabrescente, provida de domácias do tipo marsupiforme, axilar-primárias; padrão de nervação acródromo suprabasal.

Sinflorescências de $6-21 \mathrm{~cm}$ de comprimento, com pedúnculo nulo ou de 0,4 $1,3 \mathrm{~cm}$ de comprimento; bractéolas de $0,5-0,9 \mathrm{~mm}$ de comprimento, de ovadas a lanceoladas, ciliadas nos bordos e glabrescentes na face dorsal. Flores com 2,5-3mm de comprimento, subsésseis, tetrâmeras ou pentâmeras; cálice de 0,4$1,3 \mathrm{~mm}$ de comprimento, com os lobos de ápice obtuso; hipanto com 1,2-1,7mm de comprimento; pétalas com 1,3-2,1 $\mathrm{mm}$ de comprimento, com ápice arredondado; anteras com 1-1,3mm de comprimento; filetes com $1,2-1,8 \mathrm{~mm}$ de comprimento; ovário de $0,5-0,7 \mathrm{~mm}$ de comprimento, glabro; estilete com 2-2,6 $\mathrm{mm}$ de comprimento. Fruto de $2-3 \mathrm{~mm}$ de largura e comprimento, 8-10 costado; sementes de $1,8-2,1 \mathrm{~mm}$ de comprimento.

M. pusilliflora (DC.) Naud. var pusilliflora (Figs. 1, 3 e 5).

Cremanium pusilliflorum DC., Prod. 3: 194. 1828; Triana, Trans. Linn. Soc. Bot. 28:120. 1871, pro syn. M. pusilliflora Tr; Cogn. in Martius, FI. Bras. 14(4):403. 1888 , pro syn. M. pusilliflora $\mathrm{Tr}$; idem in A. et C. De Candolle, Mon. Phan. 7:864. 1891, pro syn. M. pusilliflora Tr.; Wurdack, loc. cit., pro syn. M. pusilliflora (DC.) Naud.

Chaenopleura lanceolata Gardn. in Hook., Lond. Journ. Bot. 2:349. 1843; Naud., loc. cit.:245, pro syn. $M$. gardneriana Naud.; Triana, loc. cit., pro syn. M. pusilliflora Tr.; Cogn. in Martius, loc. cit., pro syn. M. pusilliflora Tr.; idem in A. et C.
De Candolle, loc. cit., pro syn. M. pusilliflora $\mathrm{Tr}$.

Chaenopleura parviflora Gardn., loc. cit.: 348; Naud., loc. cit., pro syn. $M$. parviflora Naud.; Triana, loc. cit., pro syn. $M$. pusilliflora Tr.; Cogn. in Martius, loc. cit., pro syn. M. pusilliflora Tr.; idem in A. et C. De Candolle, loc. cit., pro syn. $M$. pusilliflora $\mathrm{Tr}$.

Chaenopleura densiflora Gardn., loc. cit.: 349; Naud., loc. cit., pro syn. M. densiflora Naud.; Triana, loc. cit., pro syn. $M$. pusilliflora Tr.; Cogn. in Martius, loc. cit., pro syn. M. pusilliflora Tr.; idem in A. et C. De Candolle, loc. cit., pro syn. $M$. pusilliflora $\mathrm{Tr}$.

Miconia Gardneriana Naud., loc. cit.; Triana, loc. cit., pro syn. M. pusilliflora Tr.; Cogn. in Martius, loc. cit., pro syn. M. pusilliflora Tr.; idem in A. et C. De Candolle, loc. cit., pro syn. M. pusilliflora Tr.

Miconia parviflora Naud., loc. cit.; Cogn. in Martius, loc. cit., pro syn. M. pusilliflora Tr.; idem in A. et C. De Candolle, loc. cit., pro syn. M. pusilliflora Tr.

Miconia densiflora Naud., loc. cit.; Cogn. in Martius, loc. cit., pro syn. M. pusilliflora Tr.; idem in A. et C. De Candolle, loc. cit., pro syn. M. pusilliflora Tr.

Miconia pusilliflora Triana, loc. cit.; Cogn. in Martius, loc. cit.:402; idem in A. et C. De Candolle, loc. cit.; Pereira, Arq. Jard. Bot. Rio Jan. 18:187, fot. 2. 1964.

Miconia pusilliflora (DC.) Naud. var major Cogn. in Martius, loc. cit.:403; idem in A. et C. De Candolle, loc. cit.:865. Syn. nov.

Folhas com margem inteira, às vezes levemente ondulada em direção ao ápice (figura 4(2)), ramos da inflorescência e hipanto com pêlos estrelados esparsos e frutos glabros.

Área de dispersão no Brasil - Nos estados do Espírito Santo, Minas Gerais, Rio de Janeiro, São Paulo, Santa Catarina e Paraná.

Espécie ocorrente em matas pluviais e capoeiras de altitude, em formações de encostas e capões de restingas. Através dos dados fornecidos pelas etiquetas de herbário ele floresce nos meses de janeiro a junho e frutifica nos meses de maio a agosto, sendo conhecida pelo nome vulgar de "Pixirica" segundo Wurdack (1962) e "Guamirim/felpudo" segundo Pio Corrêa (1926-78). Ainda de acordo com este autor a espécie em questão apresenta casca lisa, fina, pardo-escura, com ramos purpúreos quando jovens e cinzento-escuros posteriormente; fornece madeira branca, compacta, macia e leve, rachando-se facilmente durante a secagem e tendo curta durabilidade, talvez podendo ser utilizável na fabricação de papel; conhecida como "caitá" na Argentina.

De Candolle (1828) cita para Cremanium pusilliflorum "Floribus decandris" e Cogniaux (1887/88) para M. pusilliflora "floribus 5-meris". Por sua vez, Wurdack (1962) assinala para esta última espécie flores "4-meri" e questiona o caráter "5-meri", salientando que todas as cinco coleções citadas por Cogniaux possuem, predominantemente, flores tetrâmeras. Ao examinarmos o material disponível, também observamos uma maior freqüência de flores tetrâmeras para a espécie típica, enquanto que em $M$. pusilliflora var. intermedia a predominância foi de flores pentâmeras. Assim, acreditamos que neste caso também ocorra, tanto para a espécie típica quanto para a variedade, flores tetrâmeras e pentâmeras, visto uma variação semelhante de tal caráter (flores pentâmeras e hexâmeras) já ter sido assinalada por Baumgratz (1982) para espécies de seção Tamonea (Aubl.) Cogn.

Material examinado: Rio de janeiro Serra dos Órgãos, leg. Gardner 399, 400, 401 (3/1838), G, W, GH; idem, ibidem 401, S; idem, Teresópolis, leg. E. Pereira 379 (21/4/1944), RB, HB; idem, margem do rio Paquequer, leg. C. Rizzini 426 (24/2/1949), RB; Itatiaia, lote $30,800 \mathrm{~m}$, leg. A.C. Brade 18.822 (5/2/1948), HB, RB; idem, lote 88, ibidem 17.177 (17/2) 1942), RB; idem, ibidem 17.499 (25/2) 1945), RB; idem, Serra da Mantiqueira, Morro Mirante, leg. E. Pereira 56B (20/ 2/1943), HB, RB; Petrópolis, leg. Wawra 33 (1879), W; Serra de Petrópolis, variante nova, Vale do Jacob, leg. A.P. Duarte 4.671 et E. Pereira (1/4/1959), HB, RB; Teresópolis, leg. J. de Moura 177 (2/ 1888), BR; idem, leg. A. Samp. 2.352 (4/ 1917), R; idem, leg. A. Ab. 551 (2/4/ 1959), HB; Nova Friburgo, leg. P. Capell (24/1/1952), RB; Restinga de Jacarepaguá, leg. A.P. Duarte 5.240 (6/1960), HB; entre Gávea e Tijuca, leg. Glaziou 163 (4/ 5/1862), R; Canta Gallo, leg. Peckolt 303 (6/1859), BR (Holótipo de M. pusilliflora var. major); St. Antonio do Imbé, leg. A.C. Brade 11.728 et Santos Lima (4/ 1932), R; leg. Glaziou 3.967, 10.766, BR; 
ibidem 1.095 (1867), BR; ibidem 16.010 (1887), BR, G.

M. pusilliflora (DC.) Naud. var. intermedia Cogn. (Figs. 2 e 4)

Cogn. in Mart., FI. Bras. 14(4):403. 1888; idem in A. et C. De Candolle, Mon. Phan. 7:865. 1891.

Melastoma suaveolens Raddi, Melast. Bras.: 26, pl.4, fig.4. 1828 (separata da Memoire Della Societa Italiana delle Scienze 20).

Difere da espécie típica por apresentar folhas com margem dentada ou crenulada (figura 4(1)), principalmente da região mediana para o ápice, ramos da inflorescência e hipanto revestidos densamente de diminutos pêlos estrelados e frutos também com este tipo de pêlo, bem-evidente no ápice e na base.

Síntipo: Leg. Glaziou 8.458 (BR, S); Restinga de Mauá, ibidem 8.459 (1876), C, S; Genoveia, leg. Pohl 1.233 (W); Fotosintipo (F).

Área de dispersão no Brasil: nos estados do Rio de Janeiro e São Paulo.

Material examinado: Rio de janeiro leg. Glaziou 8.458, BR, S; Restinga de Mauá, ibidem 8.459 (1876), C, S; idem, ibidem 8.439 (8/6/1876), R; Genoveia, leg. Pohl 1.233, W; Suruhy, leg. J. de Moura 254 (5/1888), BR; Petrópolis, Quitandinha, leg. O.C. Gois et O. Alves s.n. (1948), RB; Itatiaia, Picada Nova, Maramba, $1.300 \mathrm{~m}$, leg. A.C. Brade 17.246 (21/3/1942), RB; idem, $1.200 \mathrm{~m}$, leg. W. D. de Barros 701 (21/3/1942), RB; São Paulo - Alto da Serra, leg. Puttemons (1907), BR.

\section{Miconia hymenonervia (Raddi) Cogn.} (Figs. 6-9)

Cogn. in Mart., FI. Bras. 14(4):399. 1888; idem in A. et C. De Candolle, Mon. Phan. 7:862. 1891; Wurd., Sell. 14:163. 1962; Per., Arq. Jard. Bot. Rio Jan. 18:188, fot. 3. 1964.

Melastoma hymenonervia Rad., Melast. Bras.:27, pl.4, fig.3. 1828 (separata da Memorie Della Societa Italiana delle Scienze 20).

Pequena árvore de $2-3 \mathrm{~m}$ de altura. Pecíolos com 0,6-1,6cm de comprimento; lâmina foliar de $6,5-17 \mathrm{~cm}$ de comprimento e $1,5-4,5 \mathrm{~cm}$ de largura, elíptica, às vezes ovada, raro oblonga, com base de aguda a cuneada, ápice atenuado, margem 2/3-serrada para o ápice e 1/3-inteira na base, membranácea, glabrescente em ambas as faces, apresentando na face dorsal domácias do tipo marsupiforme (Stace, 1965), axilar-primárias; padr̃ao de nervação acródromo suprabasal.

Sinflorescências (figura 7) de 4,5 $14,5 \mathrm{~cm}$ de comprimento, glabrescentes; pedúnculo nulo ou de $0,6-1,3 \mathrm{~cm}$ de comprimento; bractéolas de $0,6-0,9 \mathrm{~mm}$ de comprimento, de ovadas a lanceoladas, ciliadas nos bordos. Flores com 2,1-3,1 mm de comprimento, subsésseis, tetrâmeras ou pentâmeras; cálice de $0,4-0,6 \mathrm{~mm}$ de comprimento, com os lobos de ápice agudo a obtuso; hipanto de $1-1,6 \mathrm{~mm}$ de comprimento, glabrescente; pétalas de 1,3-1,9 $\mathrm{mm}$ de comprimento, com ápice de arredondado a retuso e apresentando, às vezes, pêlos estrelados em ambas as faces e no bordo; anteras de $1,2-1,8 \mathrm{~mm}$ de comprimento; filetes de $1,5-2 \mathrm{~mm}$ de comprimento; ovário de $0,6-0,8 \mathrm{~mm}$ de comprimento, glabro; estilete de 2,1. $3 \mathrm{~mm}$ de comprimento. Fruto de $2-3 \mathrm{~mm}$ de largura e comprimento, 8-10 costado, glabro, às vezes pulverulento; sementes de $2-2,3 \mathrm{~mm}$ de comprimento.

Área de dispersão no Brasil: nos estados de Minas Gerais, Rio de Janeiro, São Paulo, Santa Catarina e Paraná.

Espécie ocorrente em matas pluviais da planície litorânea. De acordo com os dados fornecidos pelas etiquetas de herbário, ela floresce nos meses de março a junho e frutifica nos meses de fevereiro a março, sendo conhecida pelo nome vulgar de "Jacatirão" segundo Wurdack (1962).

Raddi (1828) cita para Melastoma hymenonervia flores pentâmeras. Porém, examinando o material coletado por Glaziou ( $\mathrm{n}$. 1.088) e também visto por Cogniaux (1887/88), observamos apenas flores tetrâmeras. Entretanto, este utiliza em sua chave analítica, bem como na descrição de Miconia hymenonervia, o caráter "flores 5-meri". Wurdack (1962) também cita para esta espécie flores pentâmeras. Apesar de termos observado o pequeno engano cometido por Cogniaux, acreditamos que esta espécie também tenha ambos os tipos de flores, tetrâmeras e pentâmeras, como foi o concluído anteriormente para $M$. pusilliflora var. pusilliflora e var. intermedia.
Material examinado: Rio de janeiro - $\mathrm{Pe}$ trópolis, ad Retiro, leg. Glaziou 1.088 (4/ 3/1867), BR, C, R, F; idem, na mata, leg. C. Diogo $938(10 / 3 / 1965), R$; Estrada Rio-Petrópolis, leg. J.G. Kuhlmann 6.156 (25/3/1941), RB; In sylvis maritimis prope Mauá, leg. E.M. (14/5/1875), R.

\section{Miconia rigidiuscula Cogn.}

Cogn. in Mart., FI. Bras. 14(4) :398, pl. 82 fig.1. 1888; idem in A. et C. De Candolle, Mon. Phan. 7:862. 1891; Wurd., Sell. 14: 162. 1962; Per., Arq. Jard. Bot. Rio Jan. 18:187, est.4. 1964.

Árvore pequena, de $2-12 \mathrm{~m}$ de altura. Pecíolos com $0,5-1,8 \mathrm{~cm}$ de comprimento; lâmina foliar de $5-16,5 \mathrm{~cm}$ de comprimento e $1-4,5 \mathrm{~cm}$ de largura, de elíptica a lanceolada, base agudo-cuneada, ápice atenuado-caudado, às vezes falcado, margem 2/3-serrada para o ápice e 1/3-inteira na base, rígido-membranácea, glabrescente na face ventral; padrão de nervação acródromo basal ou suprabasal.

Sinflorescências de $5-13 \mathrm{~cm}$ de comprimento, com diminutos pêlos estrelados; pedúnculo nulo ou de $0,5-1 \mathrm{~cm}$ de comprimento; bractéolas de 0,3-1,2mm de comprimento, de ovadas a lineares, com pêlos estrelados na face dorsal ou apenas na margem. Flores com 2,8-3mm de comprimento, sésseis ou subsésseis, pentâmeras; cálice de 0,4-1,3mm de comprimento, com os lobos de ápice agudo; hipanto com $1,2-1,7 \mathrm{~mm}$ de comprimento, revestido de diminutos pêlos estrelados; pétalas de $1,5-2,1 \mathrm{~mm}$ de comprimento, com o ápice de obtuso arredondado, às vezes emarginado; anteras de $1,3-1,6 \mathrm{~mm}$ de comprimento; filetes de $1,8-2,1 \mathrm{~mm}$ de comprimento; ovário de $0,5-0,7 \mathrm{~mm}$ de comprimento, com pêlos estrelados no ápice; estilete de 2-2,7 $\mathrm{mm}$ de comprimento. Fruto de $2,8-3 \mathrm{~mm}$ de comprimento e $2,6-3,5 \mathrm{~mm}$ de largura, glabrescente; sementes de $2-2,5 \mathrm{~mm}$ de comprimento.

\section{M. rigidiuscula Cogn. var. rigidiuscula}

(Figs. 10-13)

M. rigidiuscula Cogn. var. parvifolia Cogn. in Mart., loc. cit.:399;idem in A. et C. De Candolle, loc. cit. Syn. nov.

Ramos, pecíolos e face dorsal da lâmina foliar glabrescentes, com os esparsos pêlos estrelados pardacentos.

Síntipo: Rio de Janeiro, leg. Glaziou 
11.967 (1881), C, G, BR, RB; Tijuca, ibidem $5.859(18 / 5 / 1872), C, B R$.

Área de dispersão no Brasil: nos estados do Rio de Janeiro, São Paulo, Santa Catarina, Paraná e Rio Grande do Sul.

Espécie crescendo em matas de altitude, capoeiras e áreas de restinga. De acordo com os dados fornecidos pelas etiquetas de herbário, ela floresce e frutifica nos meses de março a julho, sendo conhecida pelo nomes vulgares de "Pixirica" segundo Wurdack (1962) e Pio Corrêa (1926/78) e de "Pixiricão" (RB 76.145).

Material examinado: Rio de Janeiro: Mesa do Imperador, leg. A.P. Duarte 4.804 et $E$. Pereira (18/5/1959) RB idem, leg. E. Pereira 4.901 (26/5/1959), HB; Estrada da Vista Chinesa, leg. S. Tecnologia (21/5/1957), RB; Copacabana, leg. J. de Moura 125 (7/1887), BR; Tijuca, leg. Glaziou 5.859 (18/5/1872), C, BR; Serra dos Órgãos, km 6,5, leg. C. Rizzini 473 (7/3/1949), RB; idem, Picada do Frade, leg. E. Pereira 715 (4/4/1953), RB, R; leg. Glaziou 2.576 (1868), C, W, BR; ibidem 11.967 (1881). C, G, BR, RB; ibidem 16.003 (1887), BR.

\section{M. rigidiuscula Cogn. var. purpurascens}

Cogn. in Mart., FI. Bras. 14(4):399. 1888; idem in A. et C. De Candolle, Mon. Phan. 7:862. 1891.

Difere da variedade anterior por apresentar os ramos, principalmente os das extremidades da planta, pecíolos e as nervuras principais na face dorsal da lâmina foliar densamente revestidos de diminutos pêlos estrelados ferrugíneos.

Holótipo: Rio de Janeiro, leg. Glaziou 593 (1867), (BR); Isótipo: leg. Glaziou 593 (C)

Área de dispersão no Brasil: no estado do Rio de Janeiro.

Material examinado: Rio de Janeiro: Leg. Glaziou 593 (1867), BR, C.

\section{Discussão e Conclusões}

Podemos observar que ao longo da história diferentes foram as interpretações feitas quanto à caracterização dos taxa integrantes da seção Chaenanthera, princi- palmente no que diz respeito à deiscência das anteras. Em função desta característica as espécies foram, freqüentemente, agrupadas ou separadas em posições distintas e, conseqüentemente, novas seções ou subseções foram estabelecidas, o que vem a confirmar a natureza duvidosa deste caráter.

Talvez uma das principais razões que contribuiu para dificultar a delimitação dos taxa foram os termos e as expressões utilizadas para descrever, morfologicamente, a deiscência das anteras, a saber "poro in riman non abeunte" (Naudin, 1851); "poro maximo et fere ad median antherarum longitudinem in riman pro. ducto" (Naud., loc. cit.); "antherae rima unica rimisve duabus dehiscentes - scilicet poris ab apice usque ad basin loculorum productis" (Naud., loc. cit.); "poro magno deorsum in rimas $1 \mathrm{v}$. 2 longitudinales producto dehiscentes" (Benth. et Hook., 1862); "poro maximo in riman quasi birimosam antice producto dehis centes" (Cogn., 1891). Podemos perceber, desta maneira, que houve uma grande dificuldade para definir o tipo de deiscência das anteras.

Assim, através do exame criterioso dos tipos, juntamente com as respectivas descrições e caracterizações descritas nas obras princeps, concluimos que a deis cência rimosa das anteras, para as espécies desta seção, faz-se por apenas uma rima desde o ápice até a base, sobre a região do septo na face ventral.

As espécies exluídas por nós desta seção $(M$. elaeodendron, $M$. inaquidens $M$. latecrenata, $M$. sellowiana e $M$. urophylla) apresentam as anteras com um poro largo e oblíquo (figura 14), que pode, às vezes, atingir a região mediana dos lóculos na face ventral, um septo residual na área da deiscência, que se torna gradativamente inconspícuo para o ápice e an teras obovadas quando deiscentes. Wurdack (1962) já havia assinalado para $M$. sellowiana "anthers obliquely and widely 1-pored (with residual dissipiment)", salientando, no final, que esta estrutura da antera é semelhante àquela da seção Glos socentrum. Observamos que em relação às espécies excluídas por nós, este caráter é muito similar e, dentre elas, é em $M$. urophylla que ele se apresenta melhor desenvolvido (figura 14(6)). Analisando o material desta espécie, inclusive o tipo, notamos que este quando seco pode conduzir a uma identificação duvidosa, pois sugere a deiscência rimosa. Porém, vimos que esta nunca atinge a base da antera e raro ultrapassa sua região mediana.

A oportunidade de observar um exemplar de $M$. latecrenata em plena floração no Parque Nacional da Serra dos Orgãos (leg. J.F.A. Baumgratz 215 et al. RB 222.635) possibilitou-nos uma melhor interpretação de tão peculiar estrutura. Suas flores alvas apresentavam os estames dispostos radialmente, com os filetes curvos para baixo e geniculados, anteras eretas e deiscência introrsa (posição típica de anteras poricidas) (figura 14(1)). Deste modo, não podemos deixar de relacionar este tipo morfológico com sua biologia floral, principalmente no que diz respeito à adaptação aos polinizadores e sob este ponto de vista seria um procedimento por demais simplista caracterizarmos tal deiscência como rimosa apenas para facilitar nosso trabalho taxonômico, ignorando, conseqüentemente, uma tendência evolutiva do gênero Miconia, que esta deiscência evidentemente sugere. Entretanto, supomos que no processo de deiscência, sob o ponto de vista anatômico, o fenômeno da diferenciação tissular que implica na formação do poro seja semelhante àquele que ocorre numa deiscência rimosa, porém com algumas particularidades. Assim, somente após estudos ontogenéticos poderemos esclarecer a real interpretação anatômica deste processo.

Vankatesh (1955) assinalou para o gênero Mouriri (Melastomataceae) a ocorrência de um grau de transição em relação à deiscência longitudinal das anteras, salientando que este gênero apresenta uma forte tendência em restringir o comprimento da rima na região apical, indicando, deste modo, a evolução do mecanismo poricida. Semelhante comportamento também foi observado por nós no gênero Miconia, onde uma significativa e interessante plasticidade a respeito do processo de deiscência poricida, identifica nas espécies excluídas uma estrutura de transição dentro do gênero, levando-nos a concluir ser esta estrutura um estádio intermediário entre a rima propriamente dita e o poro, grau de deiscência altamente especializado e encontrado na maioria das Melastomatáceas. Conseqüentemente, estas espécies constituirão um grupo de transição dentro do gênero Miconia.

Ainda como conclusão deste nosso 
trabalho podemos assinalar que a seção em pauta está constituída de três espécies e duas variedades para a área em estudo.

M. pusilliflora (DC.) Naud. var. major foi sinonimizada $\operatorname{com}$ M. pusilliflora (DC.) Naud. var pusilliflora e $M$. rigidiuscula Cogn. var. parvifolia Cogn. com $M$. rigidiuscula Cogn. var. rigidiuscula.

Concordamos com a correção feita por Wurdack (1962) em relação ou autor da espécie $M$. pusilliflora, onde salienta que Naudin (1851) transferiu Cremanium pusilliflorum para o gênero Miconia primeiro do que Triana (1871) e que $M$. pusilliflora Beurl. trata-se, na verdade, de uma outra espécie ( $M$. beurlingii Triana). Porém, face ao já exposto anteriormente, não concordamos com este autor quando assinala para $M$. latecrenata deiscência rimosa.

As domácias, também conhecidas sob os nomes de formicárias, mirmecodomácias e bolsas foliares, ocorrem, freqüentemente aos pares, na face dorsal das folhas de $M$. hymenonervia e $M$. pusilliflora. Elas variam de tamanho, podendo ser muito pequenas ou bem-desenvolvidas e, às vezes, em algumas folhas de um mesmo exemplar, elas são incospícuas e até mesmo inexistem e, em outras, ocorrem apenas num lado da lâmina. Porém, em todos estes casos o exemplar nunca deixa de apresentá-las, não impedindo, portanto, sua correta identificação.

Nas Melastomatáceas a morfologia e orientação das nervuras principais das lâminas foliares constituem uma de suas principais características. Freqüentemente elas apresentam-se proeminentes na face dorsal e juntamente com a disposição curvinérvia e subparalela, proporcionam a existência natural de domácias. Através não só de observações de campo, como também do exame de material de herbário, podemos dizer que estas estruturas estão potencialmente presentes nesta família, principalmente nos gêneros cujas foIhas são nitidamente completas e bem desenvolvidas, como por exemplo em Miconia, Leandra, Tibouchina, Comolia, Ossaea, entre outros.

A proeminência destas nervuras, principalmente na região basal, é um fator preponderante, pois as axilas formadas pela nervura mediana com as laterais consecutivas constituem verdadeiros abrigos naturais para pequenos organismos e onde, muitas vezes, também encontramos a postura de ovos ou diminutos casulos. Nestas regiões formam-se, freqüentemente, pequenas cavidades ou reentrâncias, rasas ou profundas, em forma de $V$, não havendo necessariamente a existência de uma membrana ou bolsa especializada como nos gêneros Tococa e Topobea. Este tipo de domácia já foi assinalado por Baumgratz (1982) para algumas espécies de Miconia e observado, em campo, nos gêneros acima mencionados. Já em espécies de Leandra, Ossaea e Tibouchina por exemplo, a densa pilosidade na face dorsal das folhas, principalmente nas referidas regiões axilares, constitui, também, um perfeito abrigo para os pequenos organismos, tendo os pêlos uma importante função de apoio e proteção.

Ainda sobre estas estruturas podemos citar as observações de Schnell (1967) para duas espécies de Melastomataceae. Estudando as bolsas foliares de Maieta guianensis Aubl., assinalou que em decorrência do fenômeno da anisofilia cada nó do ramo apresentava uma folha normalmente provida de mirmecodomácia e a outra, de tamanho menor, sem a bolsa. Ele também observou tais estruturas em Tococa guianensis Aubl., associando-as com a heterofilia manifestada nos ramos de plantas jovens cultivadas, do primeiro ao quarto nó. O primeiro par de folhas não teria mirmecodomácias e a partir do segundo, haveria uma folha perfeitamente desenvolvida com uma bolsa foliar normal, enquanto a outra teria uma bolsa atrofiada. Gradativamente, esta estrutura se desenvolveria até formar um par de folhas com mirmecodomácias igualmente desenvolvidas.

Nas espécies por nós estudadas e já ci tadas acima, não observamos nenhuma dessas correlações assinaladas por Schnell Notamos que em relação a um mesmo nó as domácias podem assim se apresentarem: aos pares e idênticas em ambas as foIhas; aos pares e as de um folha serem mais desenvolvidas do que na outra; aos pares em uma folha e na outra ocorrendo apenas num lado da lâmina; aos pares em ambas as folhas, sendo uma das domácias mais desenvolvida do que sua vizinha (figura $3(1 a))$. Também é válido salientar que a ocorrência destes diferentes aspectos morfológicos pode se dar em qualquer nó dos ramos, independente de sua localização e no que diz respeito a anisofilia, este não é um caráter constante para as espécies em pauta e, portanto, nenhuma correlação pode ser feita.

Considerações anatômicas e evolutivas sobre estas estruturas foram apresentadas por Gonçalves Costa (1977) no estudo anatômico de Miconia theaezans (Bonp.) Cogn.

Outro caráter que merece ser ressaltado, refere-se ao tipo de fruto encontrado nas espécies aqui estudadas. Trata-se de um fruto carnoso, oligospérmico, com um pericarpo delgado, sem polpa sucosa envolvendo as sementes e havendo uma delimitação nítida dos lóculos pelos septos também carnosos. As sementes são bem desenvolvidas em relação ao tamanho do fruto e ocupam, praticamente, todo o espaço locular.

Miconia Ruiz et Pav. é um gênero muito bem-representado em nossa flora e sua taxonomia sempre foi considerada difícil em virtude do grande número de espécies. Vem ao encontro deste fato não só a criação de novas espécies, que muitas vezes não estão integradas nas seções estabelecidas por Cogniaux (1887/88), como também a falta de uma revisão genérica ou mesmo a nível de seção que esclareça os reais caracteres específicos. Por essa razão, acreditamos que somente através de um estudo sistematizado, constante e criterioso, novas contribuições serão dadas a tão interessante grupo, contribuindo no conhecimento de sua linha evolutiva.

\section{Abstract}

In this work the author presents a taxonomic study of the genus Miconia Ruiz et Pav., section Chaenanthera Naudin, occurring in the State of Rio de Janeiro. The tratment given to the section marks out three species and two varieties with descriptions, illustrations and photographs, emphasizing the type of dehiscence and the shape of the anthers, the occurrence of domatias, the margin of the leaves, as well as a study of the hairiness of the inflorescence, hypanthium, ovary and fruit. New synonyms are placed to $M$. pusilliflora and $M$. rigidiuscula, and a key for the recognition of the species and varieties are presented too.

\section{Bibliografia}

BAUMgRATZ, J.F.A. Miconias do Município do Rio de Janeiro. Seção Mico- 
nia DC. (Melastomataceae). Rodriguésia. Rio de Janeiro, 32 (55):73-95, 1980. il.

Miconias do Estado do Rio de Janeiro. Seção Tamonea (Aubl.) Cogniaux (Melastomataceae). Arquivos do Jardim Botânico do Rio de Janeiro. Rio de Janeiro, 26:69-86, 1982. il.

BENTHAM, G. \& HOOKER, J.D. Melastomaceae. In: Genera Plantarum. Londres, A. Black, W. Pamplin, L. Reeve \& Co., Williams \& Norgate, 1862. 1:725-773.

COGNIAUX, A. Miconia. In: Martius, Flora Brasiliensis. Monachii, Lipsiae, Frid. Fleischer, 1887-88. 14(4):212424. il.

Melastomaceae. In: A. \& C. de Candolle, Monographiae Phanerogamarum. Paris, G. Masson, 1891. 7: 1-1256.
DE CANDOLLE, A.P. Melastomaceae. In: Prodromus systematis naturalis regni vegetabilis. Paris, Treuttel et Würtz, 1828. 3:99-202.

GARDNER, G. Flora of Brazil. II - Plants from the Organ Mountains. The London Journal of Botany. London, 2 329-355, 1843

GONCALVES COSTA, C. Miconia theaezans (Bonpl.) Cogn. (Melastomataceae) - Considerações anatômicas. Rodriguésia. Rio de Janeiro, 29(43): 7-91, 1977. il.

GRISEBACH, A.H.R. Melastomaceae. In: Flora of the British West Indian Islands 1 (2):243-269, 1860.

HICKEY, L.J. Classificacion de la arquitectura de las hojas de Dicotiledoneas. Boletin da Sociedad Argentina de Botânica. La Plata, 16(1-2):1-26. 1974. il.

NAUDIN, C. Melastomacearum quae in
Musaeo Parisiensi Continentur - Monographicae Descriptionis. Annales des Sciences Naturelles. Paris, sér. 3(16): 113-246, 1851.

PEREIRA, E. Flora do Estado da Guanabara IV. Melastomataceae II. Miconieae. Gênero Miconia. Arquivos do Jardim Botânico do Rio de Janeiro. Rio de Janeiro, 18:183-214, 1964. il.

PIO CORRÊA, M. Dicionário das plantas úteis do Brasil e das exóticas cultivadas. Imp. Nacional/IBDF, 1926-78. $6 \mathrm{v}$. il.

RADDI, G. Melastome Brasiliane, Memoria. Modena, Tip. Camerale, 1828. 64p. il. (Inserida nel tomo 20 delle Memorie della Societá Italiana delle Scienze).

SCHNELL, R.G.C. Contribution à l'étude de genres Guiano-Amazoniens Tococa Aubl. et Maieta Aubl. (Melastoma-

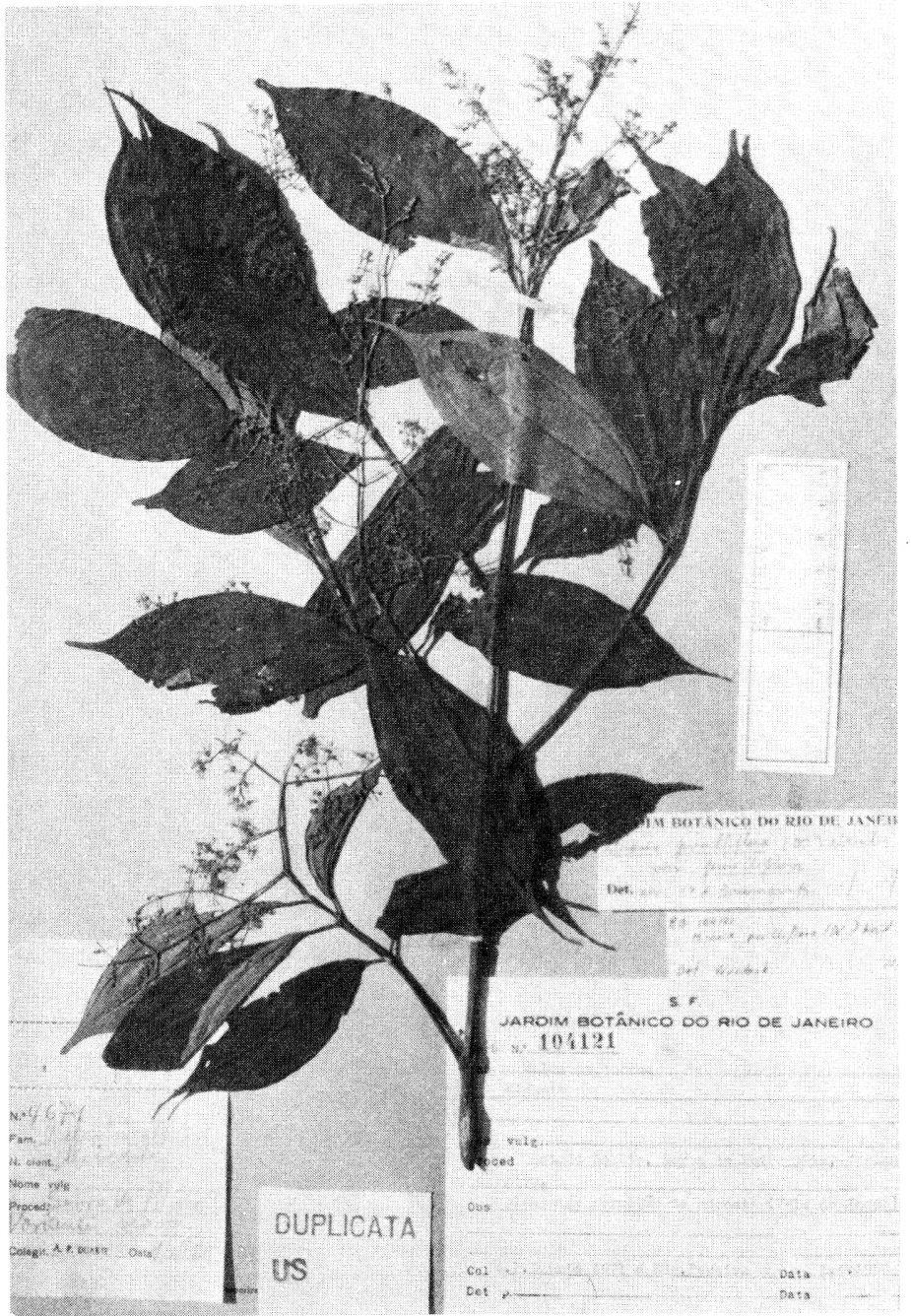

Figura 1

M. pusilliflora (DC.) Naud. var. pusilliflora

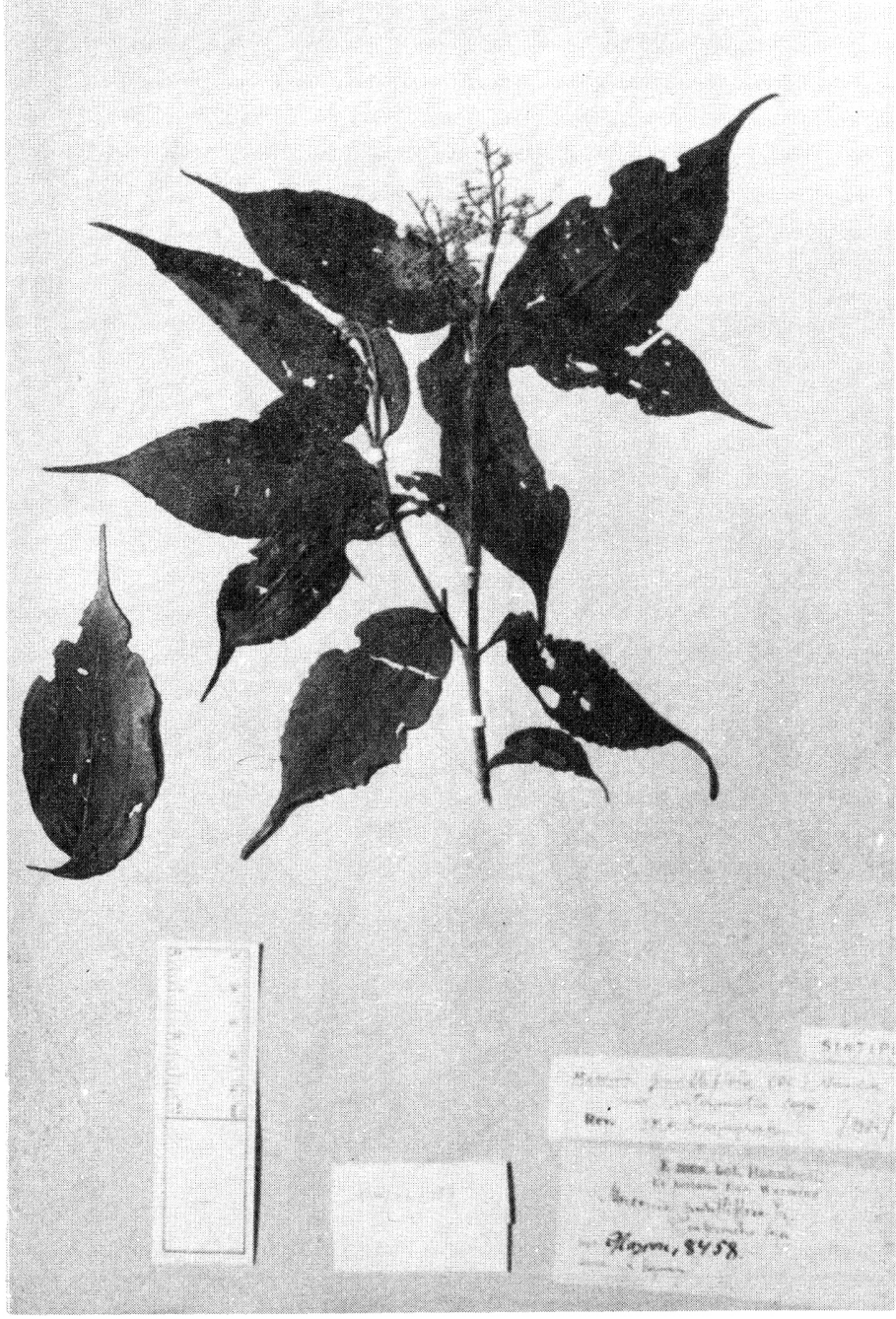

Figura 2

Síntipo de M. pusilliflora (DC.) Naud. var. intermedia Cogn. 
nieae. Gênero Miconia. Arquivos do Jardim Botânico do Rio de Janeiro. Rio de Janeiro, 18:183-214, 1964. il.

PIO CORREAA, M. Dicionário das plantas úteis do Brasil e das exóticas cultivadas. Imp. Nacional/IBDF, 1926-78. 6 v. il.

RADDI, G. Melastome Brasiliane, Memoria. Modena, Tip. Camerale, 1828. 64p. il. (Inserida nel tomo 20 delle Memorie della Societá Italiana delle Scienze).
SCHNELL, R.G.C. Contribution à l'étude de genres Guiano-Amazonieris Tococa Aubl. et Maieta Aubl. (Melastomacées) et de leurs poches foliaires. Adansonia. Paris, sér.2, 6(4):525532, 1967.

STACE, C.A. Cuticular studies as an aid to plant taxonomy. Bulletin of the British Museum (Natural History). London, Botany sér. 4(1):1-79, 1965. il.

STRITTMATTER, C.G.D. Nueva tecnica de diafanizacion. Boletin da Sociedad
Argentina de Botânica. La Plata, 15 (1) :126-129, 1973.

TRIANA, J. Melastomaceae. The Transaction of the Linnean Society of London. London, 28(1):1-188, 1871. il.

VENKATESH, C.S. The structure and dehiscence of the anther in Memecylon and Mouriri. Phytomorphology Delhi, 5(4):435-440, 1955. il.

WURDACK, J.J. Melastomataceas of Santa Catarina. Sellowia. Itajaí, 14:109218, 1962. il.

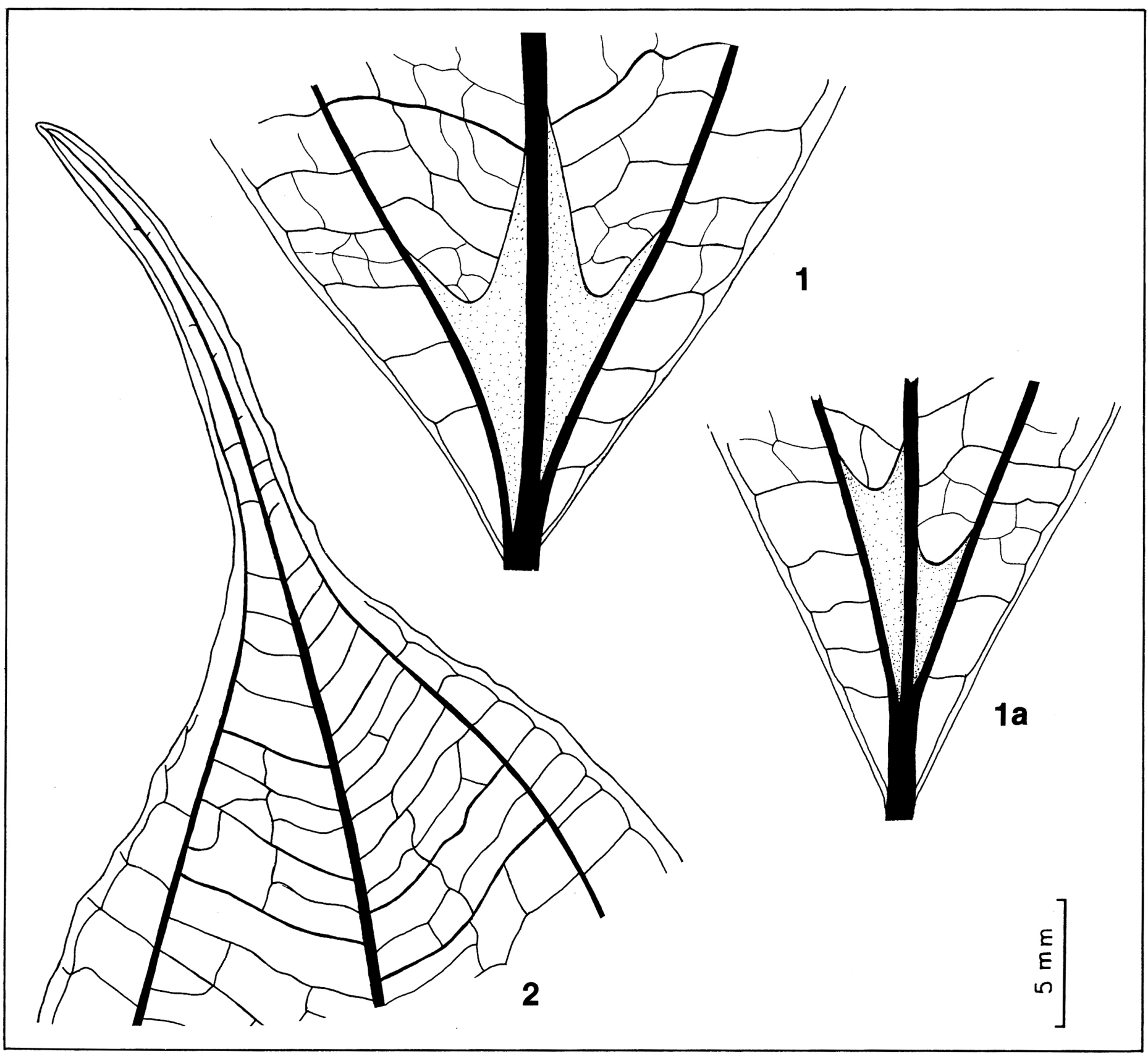

Figura 3

M. pusilliflora (DC.) Naud. var. pusilliflora: 1 e 1a - bases foliares, evidenciando sua nervação e as domácias; 2 - detalhe do ápice foliar e sua nervação. 


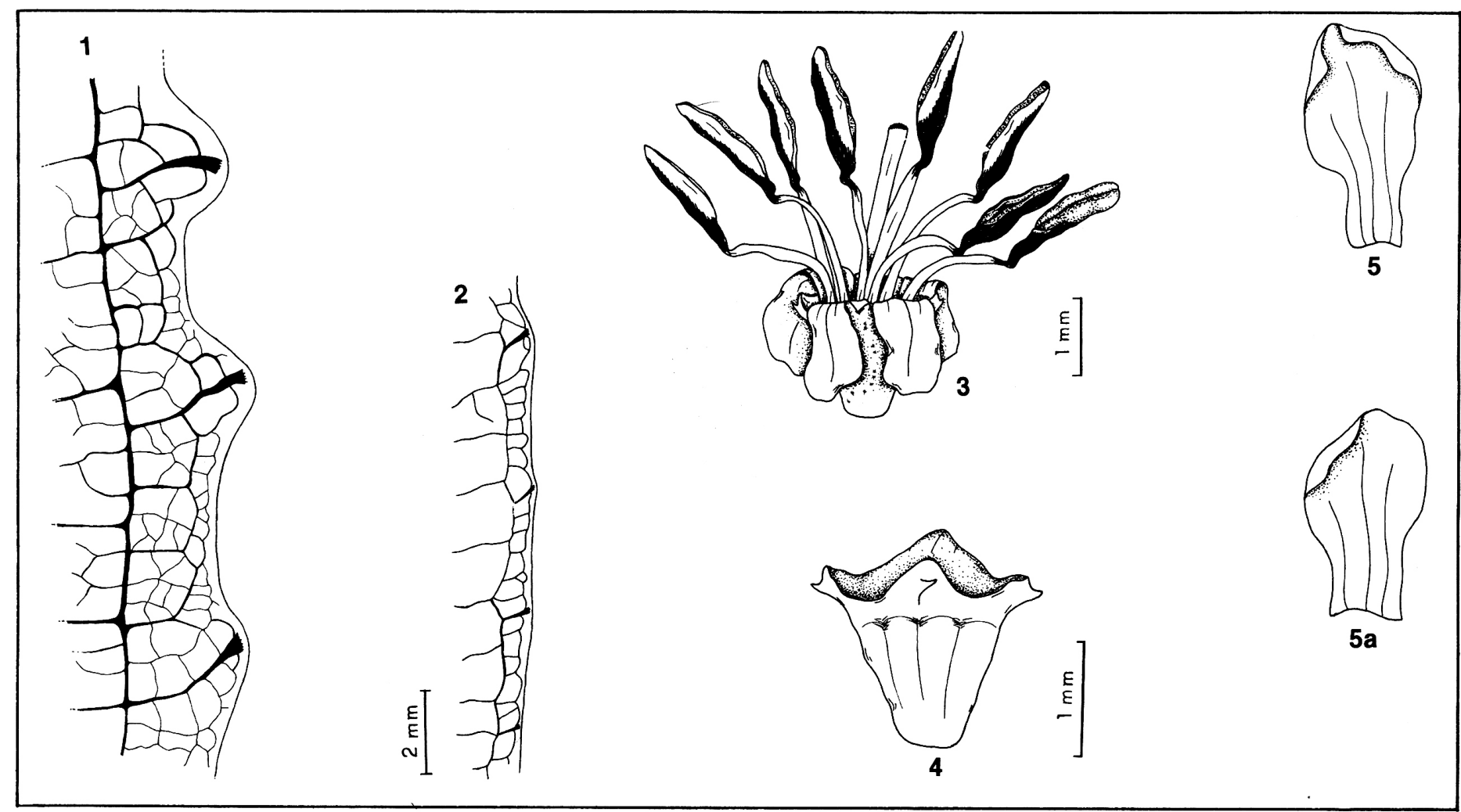

Figura 4

M. pusilliflora (DC.) Naud. var. intermedia Cogn.: 1 - detalhe da margem foliar e sua nervação; M. pusilliflora (DC.) Naud. var. pusilliflora; 2 - detalhe da margem foliar e sua nervação; 3 - flor; 4 - cálice e hipanto; 5 e 5a - pétalas.
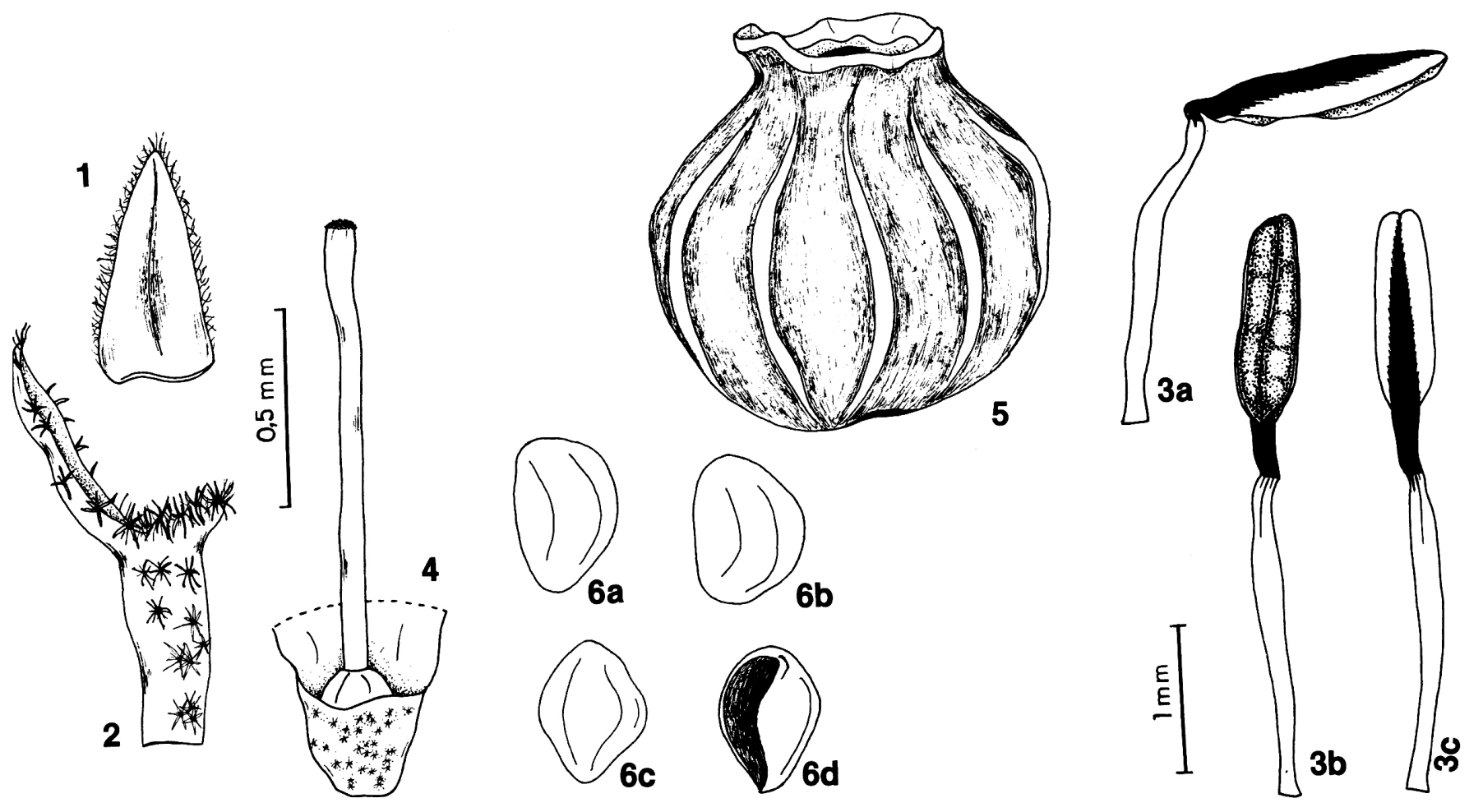

Figura 5

M. pusilliflora (DC.) Naud. var. pusilliflora: 1 - bractéola; 2 - inserção da bractéola no ramo da inflorescência; 3 - estame: a - face lateral, b - face ventral, c - face dorsal; 4 - gineceu; 5 - fruto; 6 - sementes: a, b, c - face dorsal, $d$ - face ventral. 


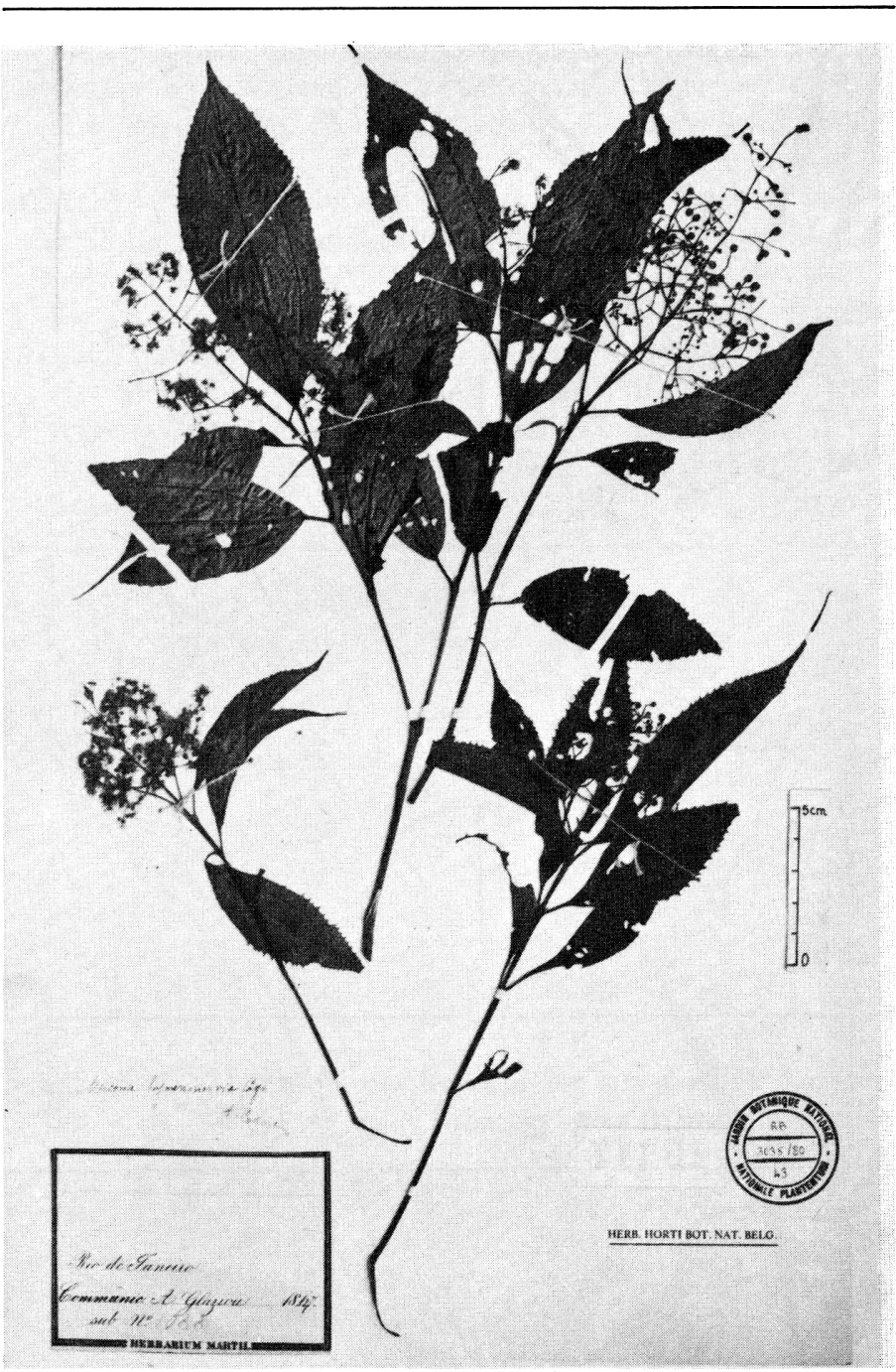

Figura 6

M. hymenonervia (Raddi) Cogn.

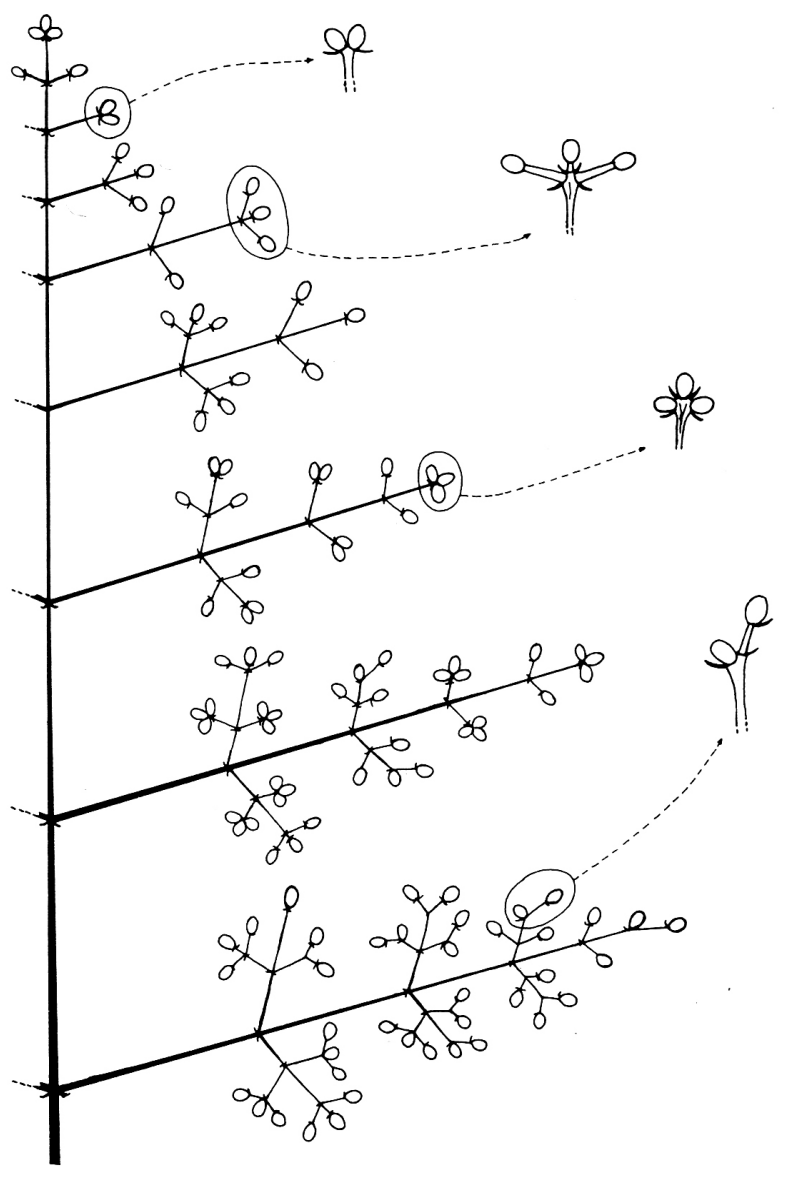

Figura 7

Esquema parcial da sinflorescência de $M$. hymenonervia, evidenciando terminações dos eixos principal e secundários.
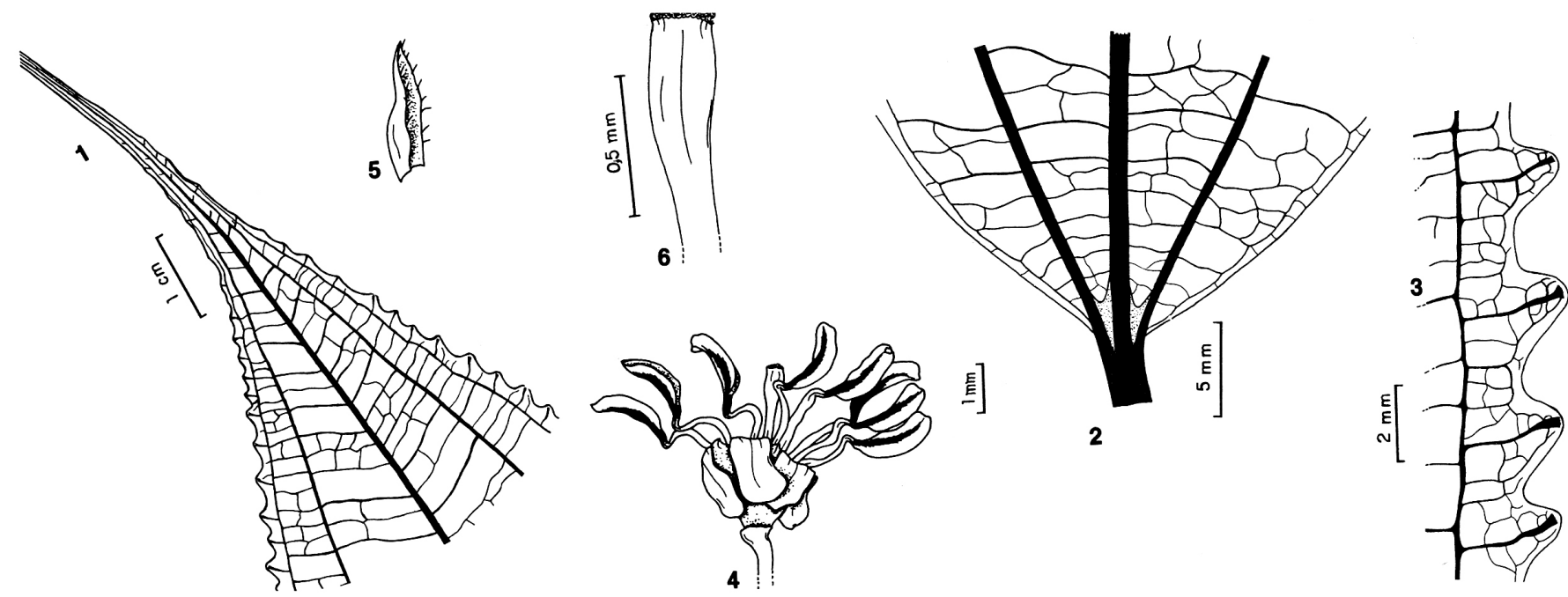

Figura 8

M. hymenonervia (Raddi) Cogn.: 1 - detalhe do ápice foliar e sua nervação; 2 - base foliar, evidenciando sua nervação e as domácias; 3 - detalhe da margem foliar e sua nervação; 4 - flor; 5 - bractéola; 6 - ápice do estilete e estigma. 


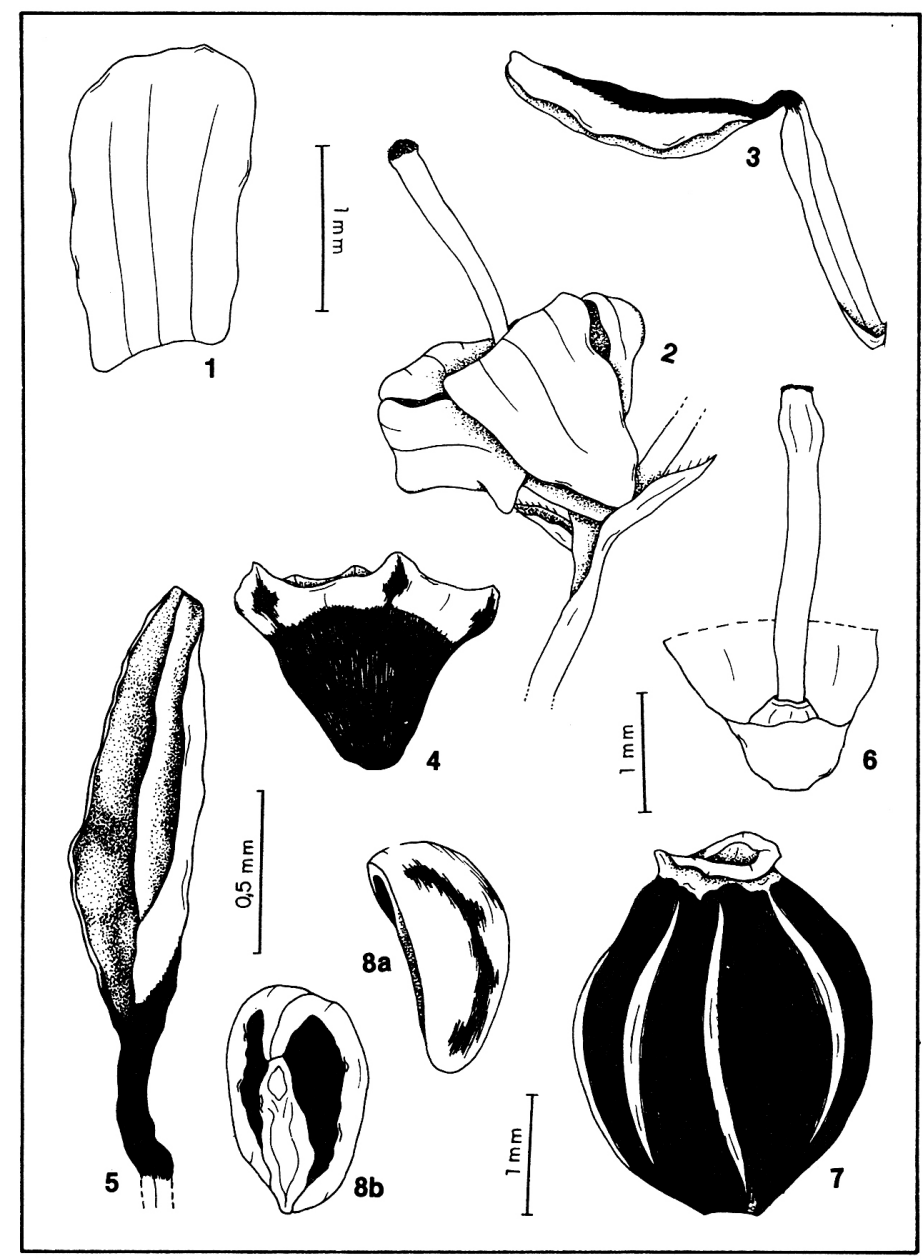

Figura 9

M. hymenonervia (Raddi) Cogn.: 1 - pétala; 2 - inserção das bractéolas e flor no ramo da inflorescência; 3 - estame; 4 - cálice e hipanto; 5 - antera; 6 - gineceu; 7 - fruto; 8 - sementes: a - face dorsal, b - face ventral.

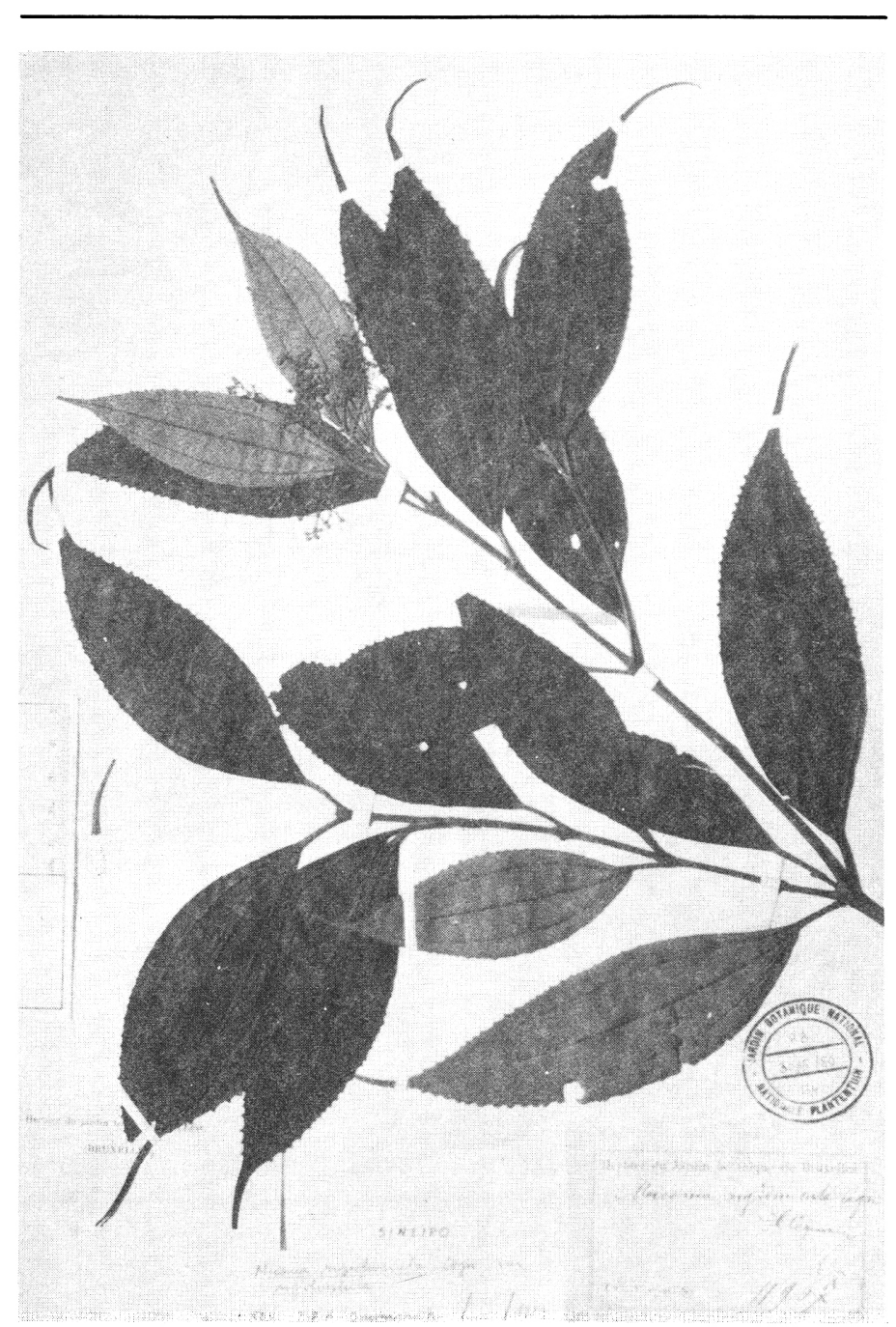

Figura 10

M. rigidiuscula Cogn. var. rigidiuscula.

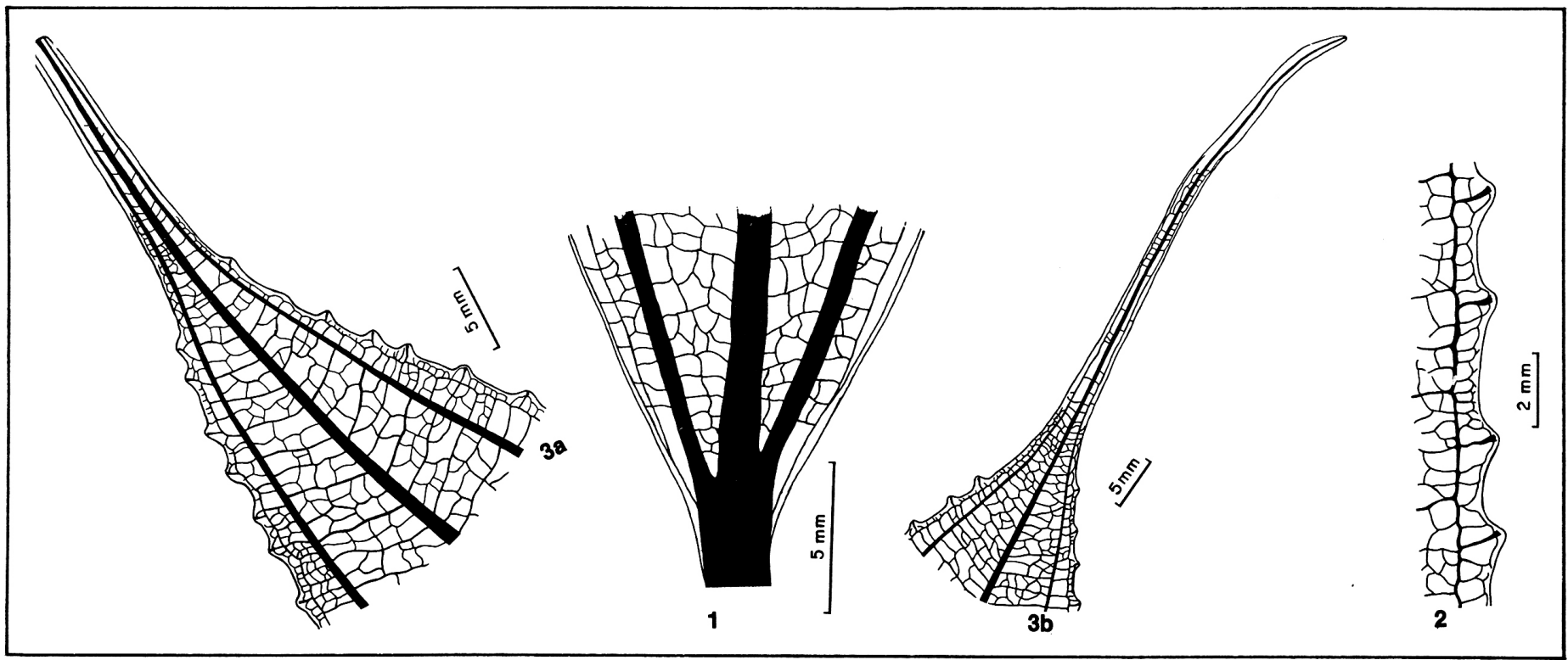

Figura 11

M. rigidiuscula Cogn. var. rigidiuscula: 1 - base foliar e sua nervação; 2 - detalhe da margem foliar e sua nervação; $3 a$ e b - detalhe dos ápices foliares e sua nervação. 


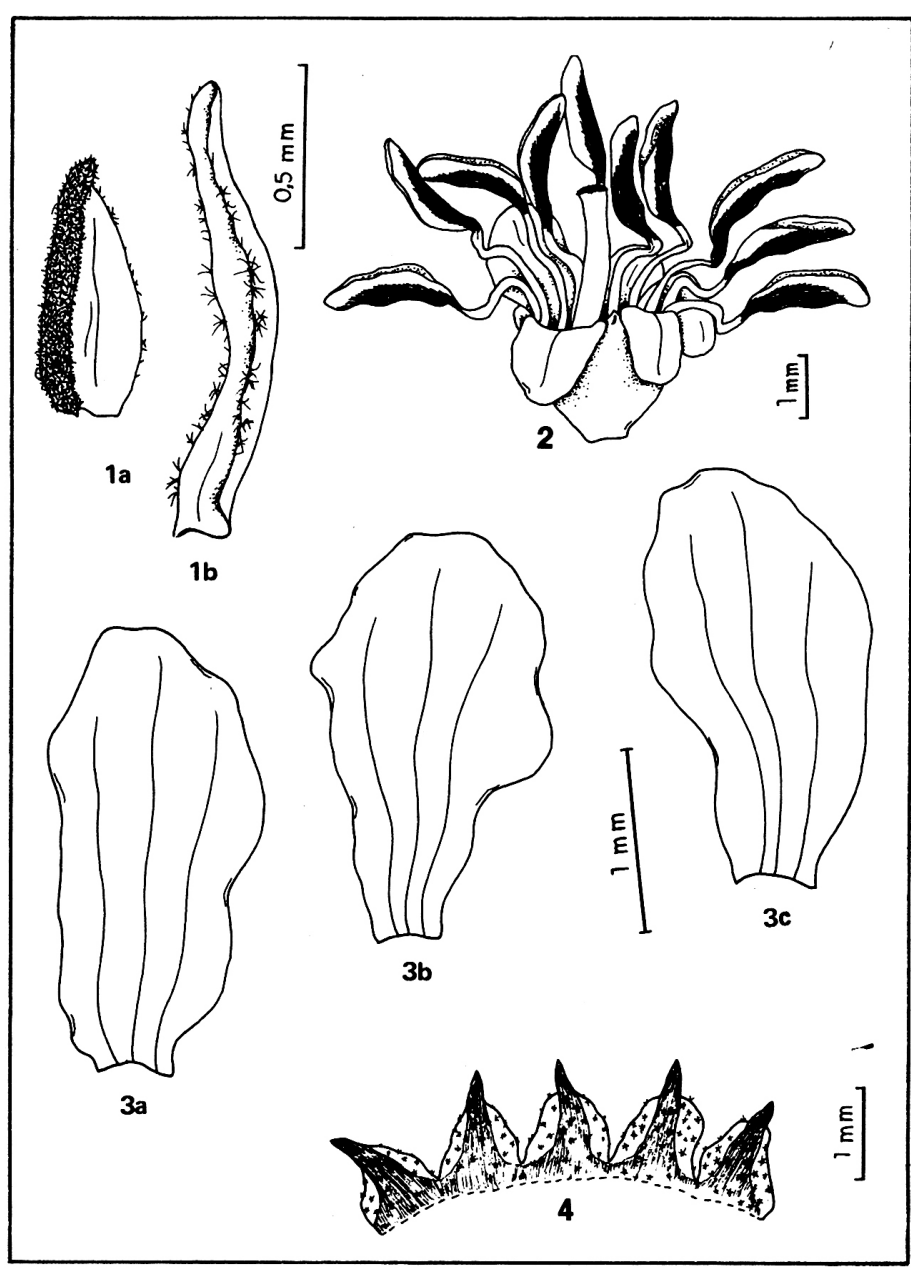

Figura 12

M. rigidiuscula Cogn. var. rigidiuscula: 1a e b - bractéolas; 2 flor; 3a, b, c - pétalas; 4 - cálice.

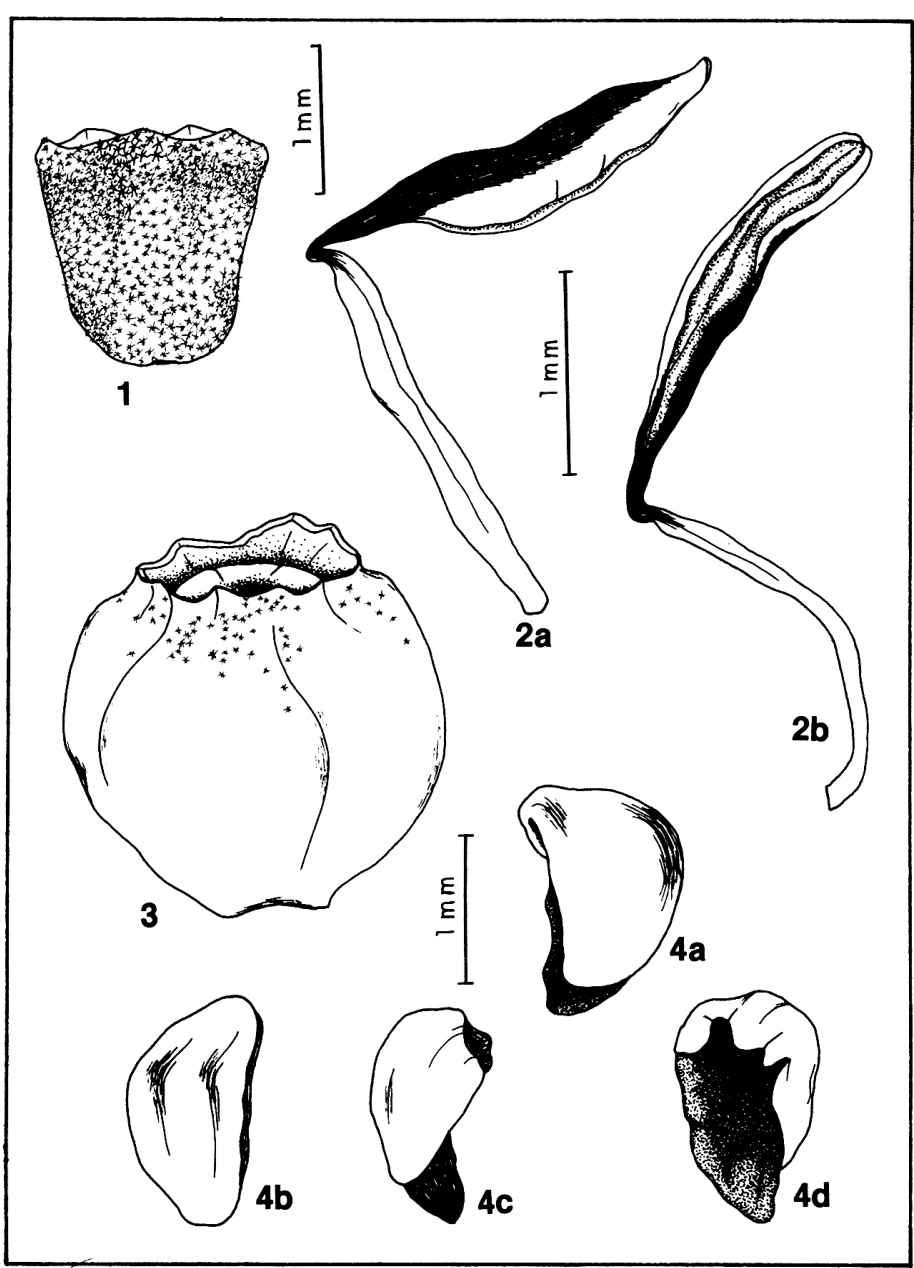

Figura 13

M. rigidiuscula Cogn. var. rigidiuscula: 1 - hipanto; $2 \mathbf{a} \mathbf{e} \mathbf{b}$ estames; 3 - fruto; 4 - sementes: a, b, c - face dorsal, d - face ventral.
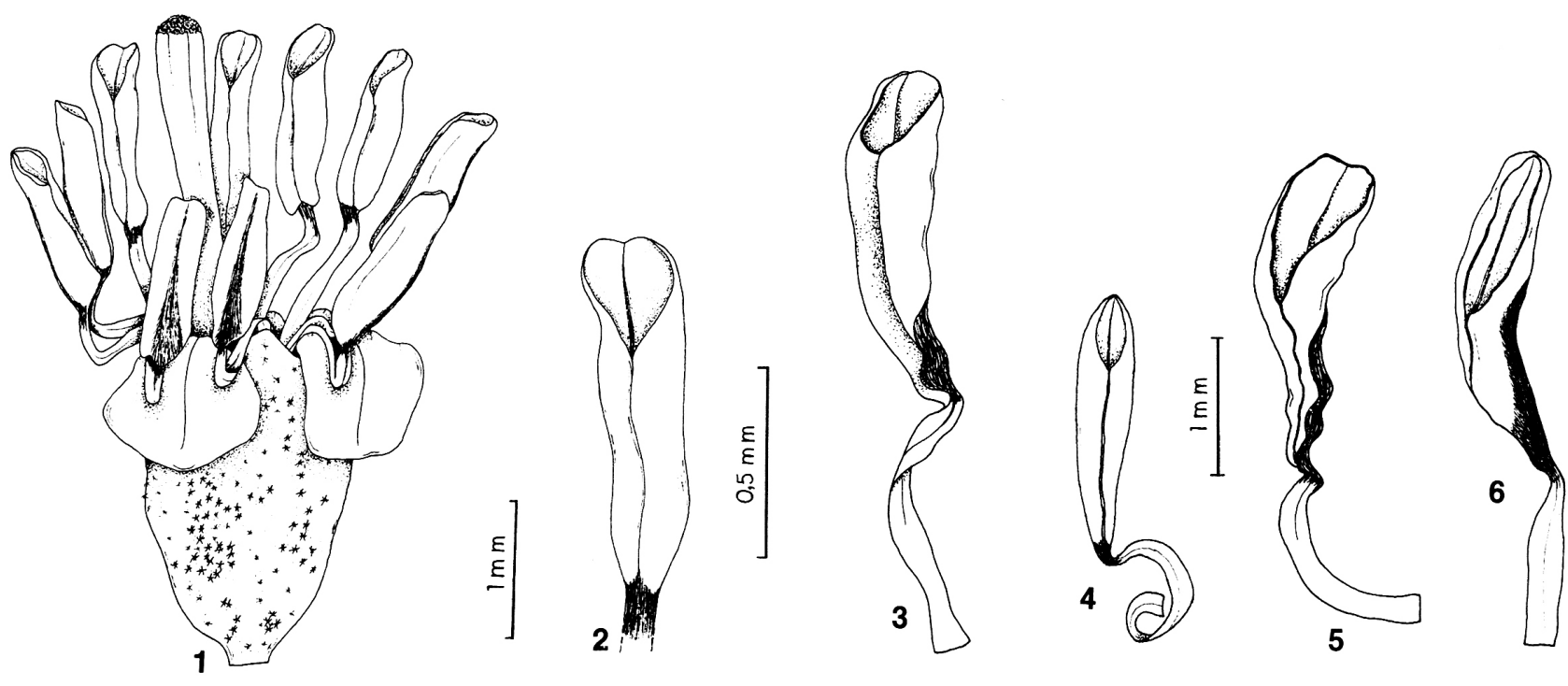

Figura 14

1 - flor de $M$. latecrenata; 2 - detalhe da antera de $M$. latecrenata; 3 - estame de $M$. sellowiana; 4 - estame de $M$. inaequidens; 5 - estame de $M$. elaeodendron; 6 - estame de $M$. urophylla. 